\title{
NOTIFICATIONS STUDY REVEALS DISCREPANCIES
}

T he Public Health Unit (PHU) of the Hunter Area Health Service receives information about notifiable infectious diseases from three groups of health service providers. These health professionals are in private practice (general practitioners and specialists), in hospitals and in laboratories. It is generally believed that, despite the legal requirements, such notifications represent only a small fraction of the real incidence of infectious diseases in the community. It was therefore considered important to carry out an audit of infectious diseases in a defined area such as the Hunter.

It was decided to carry out a study to identify any discrepancy between the number of notifications received by the PHU for specific infectious diseases and the number actually diagnosed, together with possible explanations for such discrepancies. The study would also try to identify possible impediments to optimal notification of infectious diseases under the new Public Health Act 1991.

\section{METHODS}

\section{Definition of diseases}

Specific diseases of interest for this investigation were selected from those notifiable by laboratories or by the Chief Executive Officer (CEO) of a hospital under the Public Health Act 1991. This group of diseases was chosen to explore potential barriers to notification under the new Act, even though hospital CEOs or laboratories were not required to notify any diseases during the period of the study. A comparison of certain diseases notifiable under the old and new Public Health Acts can be seen in Table 7.

\section{TABLE 7}

COMPARISON OF SOME DISEASES NOTIFIABLE UNDER THE OLD AND NEW PUBLIC HEALTH ACTS

\begin{tabular}{|c|l|l|}
\hline $\begin{array}{c}\text { PUBLIC HEALTH } \\
\text { ACT 1902 }\end{array}$ & \multicolumn{2}{|c|}{ PUBLIC HEALTH ACT } \\
\hline $\begin{array}{c}\text { Doctor- } \\
\text { notifiable }\end{array}$ & \multicolumn{1}{|c|}{$\begin{array}{c}\text { Hospital CEO- } \\
\text { notifiable }\end{array}$} & \multicolumn{1}{c|}{$\begin{array}{c}\text { Laboratory- } \\
\text { notifiable }\end{array}$} \\
\hline & $\begin{array}{l}\text { H. influenza B } \\
\text { (epiglottitis, } \\
\text { meningitis, } \\
\text { septicaemia) }\end{array}$ & $\begin{array}{l}\text { H. influenza B } \\
\text { (blood, CSF) }\end{array}$ \\
\hline Hydatid disease & Hydatid disease & \\
\hline $\begin{array}{l}\text { Legionnaires } \\
\text { disease }\end{array}$ & $\begin{array}{l}\text { Legionnaires } \\
\text { disease }\end{array}$ & Legionella species \\
\hline $\begin{array}{l}\text { Meningococcal } \\
\text { infections }\end{array}$ & $\begin{array}{l}\text { Meningococcal } \\
\text { disease } \\
\text { (meningitis, } \\
\text { septicaemia) }\end{array}$ & $\begin{array}{l}\text { Meningococcal } \\
\text { disease } \\
\text { (blood, CSF) }\end{array}$ \\
\hline Q fever & & Q fever \\
\hline
\end{tabular}

The data were defined by cases of epiglottitis, septicaemia or meningitis caused by Haemophilus influenza, of hydatid disease, of infection caused by Legionella species, of septicaemia or meningitis caused by Neisseria meningitidis and of $Q$ fever which occurred between January 1 and December 31, 1990. Measles was specifically excluded, since the 1990 outbreak in the Hunter was associated with intensive efforts by PHU staff members to obtain measles notifications from doctors, so the year 1990 could not be regarded as typical.

Definition of the study sample

The scarcity of resources made it necessary to define the study sample as all the inpatients at the Royal Newcastle Hospital (RNH) or the Mater Misericordiae Hospital (MMH) between January 1 and December 31, 1990.

\section{FIGURE 1}

SCHEMATIC ILLUSTRATION OF THE SYSTEM OF INFECTIOUS DISEASES NOTIFICATION

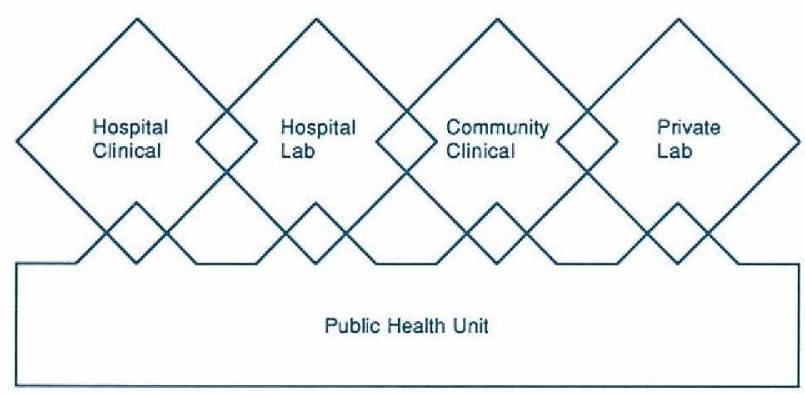

The RNH and the MMH, representing the "Hospital Clinical" source of notifications (Figure 1) were, in 1990, the Area's tertiary level hospitals for adults and children respectively, and both allowed access to computerised inpatient records. It was anticipated that cases of infectious diseases diagnosed in the hospitals would represent a substantial proportion of all cases for the whole area. In contrast, notifications to the PHU were assumed to represent all formal notifications for the area because the PHUs throughout NSW have a system of automatic transfer of notifications to the PHU of the case's residential address.

\section{RESULTS}

The results are shown in Table 8.

\section{TABLE 8}

NUMBER OF CASES OF DEFINED NOTIFIABLE DISEASES DIAGNOSED AND REPORTED TO THE PHU BY TWO HOSPITALS AND ASSOCIATED DATA

\begin{tabular}{|l|c|c|c|c|}
\hline & A & B & C & D \\
\hline DISEASE & $\begin{array}{c}\text { TOTAL } \\
\text { NOTIFIED } \\
\text { TO PHU } \\
\text { FROM ALL } \\
\text { SOURCES }\end{array}$ & $\begin{array}{c}\text { TOTAL } \\
\text { DIAGNOSED } \\
\text { BY MMH } \\
\text { AND RNH }\end{array}$ & $\begin{array}{c}\text { TOTAL } \\
\text { NOTIFIED } \\
\text { TO PHU BY } \\
\text { MMH AND } \\
\text { RNH }\end{array}$ & $\begin{array}{c}\text { \% NOTIFIED } \\
\text { MHU BY BY } \\
\text { MNH } \\
\text { RNH }\end{array}$ \\
\hline $\begin{array}{l}\text { H. influenza } \\
\text { Hydatid disease } \\
\text { Legionella sp. }\end{array}$ & 3 & 12 & - & - \\
N. Meningitidis & - & 1 & - & - \\
Q Fever & 10 & - & - & not relevant \\
\hline TOTAL & 2 & 10 & 7 & 70 \\
\hline
\end{tabular}

It may be noted that the frequencies of diagnosed cases in columns $\mathrm{B}$ and $\mathrm{C}$ for each given disease should be identical, leading to 100 per cent values in column D. $H$. influenza was not a notifiable disease in 1990. The frequencies in column A represent the total number of notifications received by the PHU for cases anywhere in the catchment area. They serve as comparison estimates for remaining frequencies. It can be seen that the selected conditions were poorly notified in 1990 .

A search of computer records from the RNH and the MMH revealed no cases of Legionella infection. However the two cases received by the PHU were traced and reviewed. One diagnosis was made in an $\mathrm{RNH}$ outpatient who was 


\section{Study reveals discrepancies}

\section{Continued from page 15}

recovering from legionnaires disease contracted in Bali, and the other was an inpatient in the $\mathrm{RNH}$ whose diagnosis of Legionella was incorrectly coded in the medical records.

These results fulfilled the first research aim. It was clear that discrepancies occurred between the number of cases diagnosed and the number reported to the PHU.

\section{DISCUSSION}

When a patient first presents to any health service provider with a disease which has been defined as notifiable, a number of events must occur before the case is added to PHU data files. First, the disease must be correctly diagnosed and recorded on the patient's medical record, whether on computer file or card file. Second, the disease must be recognised as notifiable and clearly identified as such in the record. This identification should enable a list of notifiable cases to be compiled without error, by a medical records clerk, for example. Third, information on the case must be communicated to the PHU. These three events constitute an essential chain in the notification of infectious diseases.

Chain of notification under the old Public Health Act The first event in the notification chain relates to correct diagnosis and recording. Under the old Act the responsibility for notification rested solely with clinicians. However, if laboratory confirmation of a disease was delayed, or proved negative as a result of previous antibiotic therapy, then the clinician would not be able to make a definitive diagnosis. Furthermore, if the final diagnosis is made before the final laboratory reports are filed in the records, inconsistencies can occur. In a review of the 75 MMH records classified as "unspecified septicaemia" during 1990 , it was found that on 29 occasions a pathological organism was recovered from blood cultures.

The second event in the notification chain was that the diagnosing doctor had to know that the disease was notifiable. It is difficult to estimate the extent to which visiting medical officers were aware of their legal requirements.

The third event was the notification to the PHU. In a separate audit of all paediatric CSF laboratory specimens received at the $\mathrm{MMH}$ in 1990 , four cases of Neisseria meningitidis were confirmed, but only two were transmitted to the PHU by the attending paediatrician. On one occasion a paediatrician notified the PHU of one patient, but overlooked another with the same disease. In the hospital setting it is likely that unclear lines of responsibility and communication contributed to the failure to notify. It will be useful to compare 1992 data with that of 1990 , since the new Public Health Act sets out much clearer lines of responsibility and communication.

Chain of notification under the new Act

The first essential event in the notification chain was the accurate diagnosis of an infectious disease. During examination of $\mathrm{RNH}$ records, three cases of clinical epiglottitis, diagnosed on fibreoptic endoscopy, were discovered. These cases were not included in the data of Table 1, since blood cultures were negative in each case, and therefore they did not fit the criteria of disease. Haemophilus influenza occurs in up to 100 per cent of children with clinical epiglottitis, although it is one of a few organisms which can cause disease in adults. It can be hypothesised that the three cases may have received antibiotics before blood testing, thus resulting in negative cultures. If the diagnosis of epiglottitis is based on blood cultures alone, it is possible that an epidemic of $H$. influenza epiglottitis could be missed entirely. The requirement of the new Act for hospital CEOs to notify on clinical suspicion may avert this problem.

The second event in the chain refers to the recognition of the disease as notifiable. In hospitals the person making the diagnosis may not necessarily be the notifier, and therefore diagnosis must be accompanied by some clear identifier which can uniquely indicate the notifiable status of the disease. In the hospital system, diagnoses are coded using the ninth revision of the International Classification of Diseases (ICD-9). This code could then be used as an identifier. For example $N$. meningitidis meningitis is uniquely defined under rubric 036.0 and coded as such in hospital medical records. However, two of the infectious diseases of interest in this pilot study cannot be so easily identified under this taxonomy.

The first "problem" disease is legionella pneumonia, which does not appear under such title in ICD-9. An examination of the ICD-9 index shows the disease should be included under rubric 482.8 with the descriptor "Other specified bacteria". This code also includes pneumonia due to $E$. coli and proteus. Thus legionella pneumonia cannot be identified uniquely from the numerical code.

The second disease is $H$. influenza epiglottitis. The only ICD-9 code associated with epiglottitis is 464.3 with the descriptor "Acute epiglottitis - viral epiglottitis". There is no code for bacterial epiglottits. Each of the hospitals in our study adopts different practices in coding epiglottitis ${ }^{2}$. At the RNH, a diagnosis of epiglottitis is included in the code 464.3 (viral epiglottitis), regardless of the fact that epiglottitis is almost always bacterial in origin. Staff of the MMH have been instructed to include epiglottitis under the code 464.0 (Acute laryngitis, and includes laryngitis due to pneumococcus, septic laryngitis and laryngitis not otherwise specified) if the adjective "viral" is not evident. These two policies generated ambiguity and the potential for incorrect coding.

Assuming errorless diagnosis and a unique, easily understood system of identifying relevant diseases as notifiable, the third event in the chain - the task of communicating the appropriate information to the PHU still has to be carried out under the new Public Health Act. Responsibility for this task must be clearly stated and delegated to relevant staff.

Potential barriers to notification under the new Act The new Public Health Act requires prescribed infectious diseases to be notified to the PHU by doctors on clinical suspicion, by hospital CEOs (or delegates) on clinical suspicion and by laboratories on confirmation. Similar problems might arise in all three settings, although some potential barriers occur in only one context.

First, the notifiers must be aware of their legal responsibilities. Considerable effort has been made to inform relevant medical personnel of such responsibilities by the Infectious Diseases Section of the Health Department's Epidemiology and Health Services Evaluation Branch. The section is distributing individual "user-friendly" information packages to all relevant health service personnel in the State and is promoting general media publicity. 
Second, there must be a clear channel of communication to the PHU. A recommended pathway was described in an earlier Public Health Bulletin ${ }^{4}$ and will be reinforced in the information packages.

Third, a mechanism must be developed to deal with conflicting diagnoses. The new Act requires notification by doctors and hospital CEOs on clinical suspicion. Subsequent laboratory evidence in some cases may be contradictory.

Fourth, there is the problem where laboratory tests are not developed or sensitive enough to make a diagnosis. Hepatitis $\mathrm{E}$ is notifiable by laboratories under the new Act, but there is no adequate diagnostic test.

\section{CONCLUSIONS}

It would seem appropriate to inform the Committee of Revision for the ICD about the coding problems. Until ICD-10 or subsequent taxonomy clarifies the coding for some infectious diseases, it would also seem appropriate to require diagnosticians in the hospital system to flag a disease which is notifiable by some simple device of the kind suggested.

It is also time that medical records in all hospital and laboratory facilities were computerised, if only in the name of accountability by audit. It would be inordinately expensive to carry out an audit if searches were hand-made.

The impediments to effective disease notification discussed here relate only to cases from the source "Hospital Clinical" shown in Figure 1. Further barriers may be encountered in cases from the other three sources. Elucidation of these barriers could be achieved by extending this study to include all souces of diagnoses.

\section{RECOMMENDATIONS}

\section{It is recommended that:}

- a report be made to representatives of the Committee of Revision for the ICD, relating to specific coding problems;

- a clear and uniform plan be established for the identification and transmission of infectious diseases to the PHU in each hospital in NSW; all patient records in Health Department facilities be computerised in a uniform manner; and

- all pathology records pertaining to notifiable diseases be maintained on computer and regularly examined by PHU staff. Such a scheme has been recently development in the Hunter Area Pathology Service.

Rosemary Aldrich, Registrar,

Department of Microbiology and Infectious Diseases, Hunter Area Health Service

Thais A Miles, Registrar,

Public Health Unit, Hunter Area Health Service

(seconded from the Evidemiology and Health Services Evaluation Branch of the NSW Health Department)

1. Burns JE, Hendley JO. Epiglottitis. In Mandell GL, Douglas RG, Bennett JE (eds). Principles and practice of infectious diseases. Churchill Livingstone, New York, 1990.

2. Personal communication, staff of the RNH and the MMH

3. Personal communication, C. Roberts and S. Jobson.

4. Roberts C, Rubin G, Levy M. Improving infectious diseases control.

4. Roberts C, Rubin G, Levy M. Improving

\section{Midwives' Data Collection}

\section{Continued from page 14}

\section{TABLE 5}

MOTHER'S HEALTH AREA/REGION OF RESIDENCE ALL BIRTHS NOTIFIED TO THE NSW MDC, JANUARY-JUNE 1990

\begin{tabular}{|l|c|c|}
\hline Area/Region & Number of births & Per cent \\
\hline Central Sydney & 2,092 & 4.9 \\
Northern Sydney & 3,859 & 9.0 \\
Southern Sydney & 3,437 & 8.0 \\
Eastern Sydney & 1,994 & 4.6 \\
Western Sydney & 4,656 & 10.8 \\
Wentworth & 2,249 & 5.2 \\
Sth-Western Sydney & 5,679 & 13.2 \\
Central Coast & 1,807 & 4.2 \\
Hunter & 3,438 & 8.0 \\
Illawarra & 2,546 & 5.9 \\
North Coast & 2,693 & 6.3 \\
New England & 1,736 & 4.0 \\
South-East & 1,416 & 3.3 \\
South-West & 1,667 & 3.9 \\
Central West & 1,326 & 3.1 \\
Orana Far West & 1,264 & 2.9 \\
Outside NSW & 1,110 & 2.6 \\
\hline
\end{tabular}

\section{TABLE 6}

MOTHER'S COUNTRY OF BIRTH ALL BIRTHS NOTIFIED TO THE NSW MDC, 1987 AND JANUARY-JUNE 1990

\begin{tabular}{|l|r|r|c|}
\hline Country of birth & $\begin{array}{c}\text { Number of } \\
\text { births (Jan- } \\
\text { June 1990) }\end{array}$ & $\begin{array}{c}\text { Per cent } \\
\text { (Jan-June } \\
\mathbf{1 9 9 0 )}\end{array}$ & $\begin{array}{c}\text { Per cent } \\
(1987) \\
\mathbf{n = 8 2 , 1 2 6}\end{array}$ \\
\hline Australia & 31,053 & 73.0 & 73.0 \\
(non-Aboriginal) & 513 & 1.2 & 1.6 \\
Australia (Aboriginal) & 1,435 & 3.4 & 3.1 \\
New Zealand/Oceania & 3,309 & 7.8 & 9.5 \\
Europe & 2,822 & 6.7 & 5.5 \\
Asia & 1,624 & 3.8 & 3.9 \\
Middle East & 488 & 1.2 & 1.2 \\
America & 347 & 0.8 & 0.9 \\
Africa & 790 & 1.9 & 1.3 \\
Not stated & \multicolumn{3}{|c}{} \\
\hline
\end{tabular}

\section{MATERNAL COUNTRY OF BIRTH}

Births to women born in Europe declined in January-June 1990 compared with 1987 , while births to women born in Asia increased. Births to Aboriginal women also appeared to fall, although there may have been under-reporting of Aboriginality (Table 6).

Public Health Unit directors receive data, when processed and checked, on all births to residents of the Health Areas or Regions which they serve. These data, which do not contain any personal identification items, enable PHUs to investigate pregnancy outcomes and associated factors on a local basis. Requests for Area/Regional and local information on pregnancy outcomes should be directed to PHUs in the first instance.

Margaret Pym, Pamela Adelson, Ru Nguyen, Michael Frommer Epidemiology and Health Services Evaluation Branch NSW Health Department

1. Kearney M et al. NSW Maternal and Perinatal Collection Half-Yearly Report January-June 1986. NSW Health Department, Sydney, 1989.

2. Kearney M et al. 1987 Maternal and Perinatal Report. NSW Health Department, Sydney, 1990. 